\title{
Cost Effectiveness of Mirabegron Compared with Tolterodine Extended Release for the Treatment of Adults with Overactive Bladder in the United Kingdom
}

\author{
Samuel Aballéa - Khaled Maman - Katia Thokagevistk • \\ Jameel Nazir • Isaac A. O. Odeyemi • \\ Zalmai Hakimi $\cdot$ Andy Garnham $\cdot$ Mondher Toumi
}

Published online: 10 December 2014

(C) The Author(s) 2014. This article is published with open access at Springerlink.com

\begin{abstract}
Background Overactive bladder (OAB) is highly prevalent and is associated with considerable morbidity and reduced health-related quality of life. $\beta_{3}$-adrenergic receptor $\left(\beta_{3}-\mathrm{AR}\right)$ stimulation is a novel alternative to antimuscarinic therapy for OAB.

Objective The objective of this analysis was to assess the cost effectiveness of the $\beta_{3}$-AR agonist mirabegron relative
\end{abstract}

Presented in part at ISPOR 16th Annual European Congress, 2-6 November 2013, Dublin, Ireland.

Electronic supplementary material The online version of this article (doi:10.1007/s40261-014-0240-z) contains supplementary material, which is available to authorized users.

S. Aballéa $(\bowtie) \cdot K$. Thokagevistk $\cdot$ M. Toumi

Creativ-Ceutical SARL, 215, rue du Faubourg St-Honoré, 75008

Paris, France

e-mail:sab@creativ-ceutical.com

K. Maman

Creativ-Ceutical Ltd., London, UK

J. Nazir · I. A. O. Odeyemi · A. Garnham

Astellas Pharma Europe Ltd., Chertsey, Surrey, UK

Z. Hakimi

Astellas Pharma Global Development, Leiden, The Netherlands to tolterodine extended release (ER) in patients with $\mathrm{OAB}$ from a UK National Health Service (NHS) perspective. Methods A Markov model was developed to simulate the management, course of disease, and effect of complications in OAB patients over a period of 5 years. Transition probabilities for symptom severity levels and probabilities of adverse events were estimated from the results of the randomised, double-blind SCORPIO trial in 1,987 patients with OAB. Other model inputs were derived from the literature and on assumptions based on clinical experience.

Results Total 5-year costs per patient were $£ 1,645.62$ for mirabegron $50 \mathrm{mg} /$ day and $£ 1,607.75$ for tolterodine ER $4 \mathrm{mg} /$ day. Mirabegron was associated with a gain of 0.009 quality-adjusted life-years (QALYs) with an additional cost of £37.88. The resulting incremental cost-effectiveness ratio (ICER) was $£ 4,386 / \mathrm{QALY}$ gained. In deterministic sensitivity analyses in the general OAB population and several subgroups, ICERs remained below the generally accepted willingness-to-pay (WTP) threshold of $£ 20,000 /$ QALY gained. The probability of mirabegron $50 \mathrm{mg}$ being cost effective relative to tolterodine ER $4 \mathrm{mg}$ was $89.4 \%$ at the same WTP threshold.

Conclusions Mirabegron $50 \mathrm{mg} / \mathrm{day}$ is likely to be cost effective compared with tolterodine ER $4 \mathrm{mg} /$ day for adult patients with OAB from a UK NHS perspective. 


\section{Key Points}

Overactive bladder $(\mathrm{OAB})$ is a common condition that increases in prevalence with age and has a significant negative impact on quality of life.

For the past 40 years, antimuscarinic agents have been the mainstay of therapy for $\mathrm{OAB}$; however, unmet efficacy expectations and side effects, particularly dry mouth, limit persistence with antimuscarinic therapy.

Recently, an alternative to antimuscarinic agents has received marketing authorisation; the $\beta_{3}$-adrenergic receptor agonist mirabegron is associated with at least similar efficacy to most antimuscarinic therapies and also has a lower incidence of dry mouth.

No economic analyses of mirabegron compared to antimuscarinic agents in the treatment of $\mathrm{OAB}$ have been performed; therefore, we developed a model to analyse the cost effectiveness of mirabegron $50 \mathrm{mg} /$ day relative to currently available antimuscarinic agents for the treatment of $\mathrm{OAB}$ from a UK National Health Service perspective.

The model captured the effects of variations in symptom severity over time on quality of life and the influence of treatment discontinuation and switch on costs and health outcomes, as well as direct treatment costs.

Compared to tolterodine extended release $4 \mathrm{mg}$, mirabegron $50 \mathrm{mg}$ was cost effective, with an approximately $90 \%$ probability of cost effectiveness at a willingness-to-pay threshold of $£ 20,000$.

\section{Introduction}

Overactive bladder $(\mathrm{OAB})$ is a symptom-defined condition characterised by urinary urgency, usually with urinary frequency and nocturia, and sometimes with urgency incontinence [1]. Urinary urgency is particularly bothersome for persons with $\mathrm{OAB}$ [2]. OAB is highly prevalent, with a frequency that increases with age. An estimation model based on sex- and age-stratified prevalence data and International Continence Society definitions [3] suggested that the overall prevalence of OAB was $10.7 \%$ in 2008 and predicted an increase of $20.1 \%$, from 455 to 546 million, by the year 2018 [4]. This followed earlier data from a population-based survey based on 16,776 interviews in six European countries that showed an overall prevalence of OAB symptoms of $16.6 \%$ in persons aged $\geq 40$ years [5].

Patients with $\mathrm{OAB}$ have decreased health-related quality of life (HRQoL), including health-related work impairment, depression and sexual/relationship difficulties $[2,6$, 7]. Anxiety and depression are strongly associated with $\mathrm{OAB}$ [7], and patients report significant social, psychological, occupational, domestic and physical stigma [8]. The prevalence of OAB and its effects on HRQoL means that effective therapy is needed.

Treatment options for OAB include conservative management (lifestyle advice, bladder training, etc.), followed by drug therapy and surgery where required; the primary pharmacological option has traditionally been muscarinic receptor antagonist therapy (antimuscarinic drugs; e.g. oxybutynin, tolterodine and solifenacin) [9-11]. These inhibit abnormal detrusor contractions in the bladder, but also inhibit muscarinic receptors elsewhere in the body, such as the salivary glands, tear ducts, brain and heart, to varying degrees [12]. This non-specificity results in adverse events, the most common and troublesome of which are dry mouth, blurred vision and constipation [12, 13]. Adverse events, together with unmet efficacy expectations, are the primary reasons for discontinuation of antimuscarinic drugs [13]. Therefore, alternative approaches to $\mathrm{OAB}$ therapy have been developed and approved, the most important of which is $\beta_{3}$-adrenergic receptor $\left(\beta_{3}\right.$-AR) stimulation to promote storage of urine in the bladder via detrusor relaxation [14].

The $\beta_{3}$-AR agonist mirabegron (Betmiga ${ }^{\mathrm{TM}}$; Astellas) has been shown in phase III trials to be effective and well tolerated in the management of OAB [15-18]. These trials showed that mirabegron therapy significantly improves outcomes such as the number of incontinence episodes and micturitions per $24 \mathrm{~h}$ compared to placebo at 12 weeks [15-17], and is well tolerated with sustained efficacy for up to 12 months [18]. In trials in which patients were randomised to mirabegron, tolterodine or placebo, the incidence of dry mouth with tolterodine was at least threefold that with mirabegron $[15,18]$. In these trials, tolterodine produced mean decreases in the number of incontinence episodes and micturitions per $24 \mathrm{~h}$ that were not significantly greater than those with placebo at 12 weeks, but were similar to those with mirabegron at 12 months [15, 18].

Economic analyses comparing different treatments are now an important factor in making decisions regarding purchasing, pricing, reimbursement and formulary acceptance. To date, however, no economic analyses of mirabegron in the treatment of OAB have been published. Therefore, a Markov model was developed to analyse the cost effectiveness of mirabegron $50 \mathrm{mg} /$ day relative to 
currently available antimuscarinic agents for the treatment of $\mathrm{OAB}$. We describe the model in detail and report an analysis of the cost effectiveness of mirabegron $50 \mathrm{mg}$ compared with tolterodine extended release (ER) $4 \mathrm{mg}$ in adult patients with OAB from a UK National Health Service (NHS) payer perspective.

\section{Methods}

\subsection{Model Overview}

A Markov model was developed to simulate the therapeutic management, course of disease, and effect of complications in hypothetical cohorts of OAB patients over a 5-year period (Supplementary Figure 1). Several existing models based on a structure developed by Kobelt et al. [19] were already available, but were limited to a time horizon of 1 year and did not model treatment pathways after drop-out. Thus, differences in costs and outcomes related to treatments used after withdrawal could not be accurately estimated. We captured the influence of treatment discontinuation and switch on costs and $\mathrm{OAB}$ symptoms. This is particularly important because persistence with antimuscarinic agents affects HRQoL, health status and healthcare resource utilisation [20]. HRQoL was assumed to be dependent on both variations in symptoms over time and the side effects of treatment.

\subsection{The SCORPIO Trial}

SCORPIO was a randomised, double-blind, parallel group, placebo- and active-controlled phase III trial carried out in 27 countries in Europe and Australasia to compare the efficacy and safety of mirabegron 50 and $100 \mathrm{mg}$ daily with those of placebo in patients with $\mathrm{OAB}$ treated over 12 weeks [15]. The co-primary endpoints were the change from baseline to final visit in the mean number of incontinence episodes and micturitions per $24 \mathrm{~h}$. Assessment of safety and tolerability was a secondary endpoint. A secondary comparison of the efficacy and safety of treatment with tolterodine ER $4 \mathrm{mg}$ daily and placebo was also performed.

In total, 1,987 patients were randomised. Mirabegron produced statistically significant $(p<0.05)$ improvements (adjusted mean change from baseline [95\% confidence intervals]) compared with placebo in terms of number of incontinence episodes per $24 \mathrm{~h}(50 \mathrm{mg}:-1.57$ [ -1.79 to -1.35 ]; placebo -1.17 [ -1.39 to -0.95$]$ ) and number of micturitions per $24 \mathrm{~h}(50 \mathrm{mg}$ : -1.93 [ -2.15 to -1.72$]$; placebo -1.34 [ -1.55 to -1.12$]$ ). Statistically significant improvements were also noted for other key efficacy endpoints and HRQoL outcomes. Incidences of treatmentemergent adverse events were similar across treatment groups, but the incidence of dry mouth with mirabegron $50 \mathrm{mg}$ was similar to placebo (2.8 and $2.6 \%$, respectively), whereas it was more than threefold higher in patients receiving tolterodine ER $4 \mathrm{mg}(10.1 \%)$ [15].

\subsection{Model Description}

The model was programmed to run in Microsoft Excel 2007 (Microsoft Corp., Redmond, WA, USA). The treatment pathway, based on the model described above, for the analysis is shown in Fig. 1. Transitions are shown in more detail in Supplementary Figure 1. The model simulated changes in symptoms (frequency of micturitions and incontinence episodes, for which the model was run in parallel) at monthly intervals (i.e. 60 cycles over 5 years). Every month, patients could remain on treatment (mirabegron or tolterodine), switch to a treatment with efficacy and price similar to solifenacin or discontinue (i.e. go to 'no treatment'). A small proportion received botulinum toxin (BTX) after this next line of therapy (this transition was not allowed directly after mirabegron or tolterodine). The probabilities of switch and discontinuation were dependent on adverse events. Patients with adverse events could stay on treatment, but incurred a disutility. Patients who discontinued treatment could naturally improve and thereby transition to a lower severity category after 1 month, or could worsen or stay the same. These patients could also restart their previous treatment, could move to a new treatment, or remain off treatment. In the event of success on BTX, patients were assumed to move to the lowest level of severity and remain there until the end of the simulation.

The model accounted for the differences in probability of improving or worsening between the short- and longterm. Thus, the probability of improvement was greatest in the first month after treatment initiation, after which it decreased progressively, and was then assumed constant after 3 months.

Several populations were considered. Any patient presenting with OAB formed the base case population. Other populations considered were patients dissatisfied with previous treatment, patients dissatisfied with previous treatment due to lack of efficacy, patients dissatisfied with previous treatment due to intolerance, treatment-naïve patients, elderly patients, female patients, male patients and incontinent patients.

\subsection{Model Input Parameters}

All model input parameters are presented in detail in Supplementary Table 1. 
Fig. 1 Markov treatment pathway. $B T X$ botulinum toxin, $E R$ extended release, $O A B$ overactive bladder syndrome

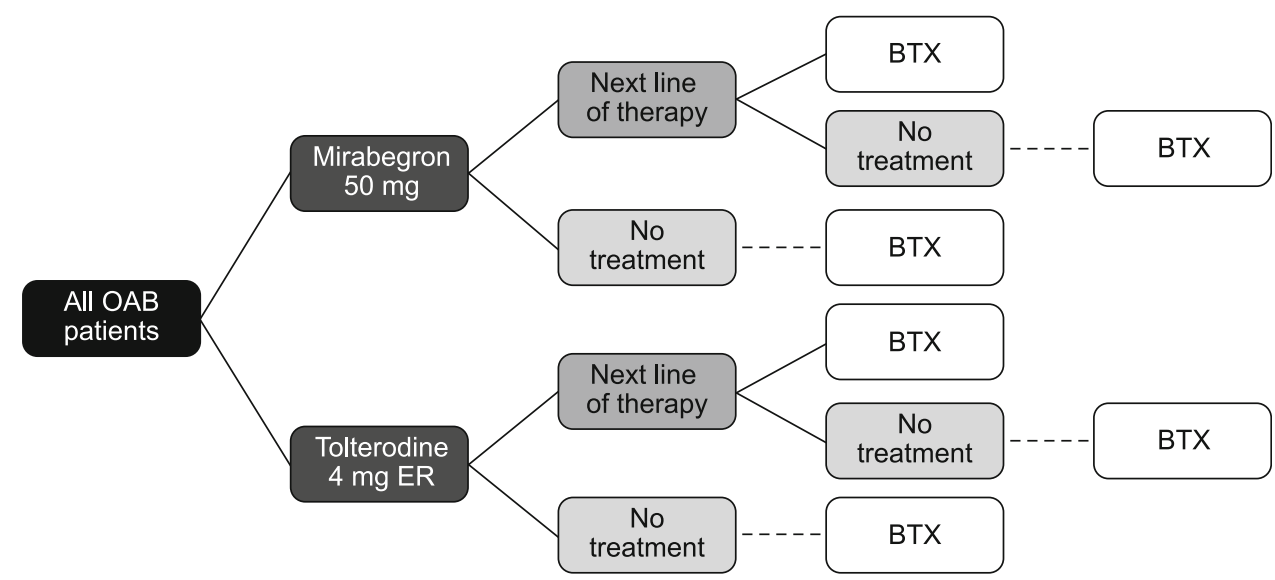

Table 1 Symptom severity levels. Definitions and distribution of patients at baseline

\begin{tabular}{lll}
\hline $\begin{array}{l}\text { Symptom severity } \\
\text { level }\end{array}$ & $\begin{array}{l}\text { Mean episodes/day } \\
(n)\end{array}$ & $\begin{array}{l}\text { Proportion of patients } \\
(\%)\end{array}$ \\
\hline Micturition & & \\
1 & $\leq 8$ & 6.30 \\
2 & $>8-10$ & 30.69 \\
3 & $>10-12$ & 27.18 \\
4 & $>12-14$ & 19.46 \\
5 & $>14$ & 16.37 \\
Incontinence & & \\
1 & 0 & 38.87 \\
2 & $>0-1$ & 18.84 \\
3 & $>1-2$ & 14.64 \\
4 & $>2-3$ & 9.18 \\
5 & $>3$ & 18.47 \\
\hline
\end{tabular}

\subsubsection{Symptom Severity}

Symptoms (micturition frequency and incontinence) had five levels of severity (Table 1). Initial proportions of patients with symptoms of each severity were derived from SCORPIO [15]. Transition probabilities between symptom levels for mirabegron $50 \mathrm{mg}$ and tolterodine ER $4 \mathrm{mg}$ were estimated by applying multinomial logistic regression models to the SCORPIO trial data (see Electronic Supplementary Material and Supplementary Tables 2 and 3).

\subsubsection{Treatment Persistence, Switching and Restarting}

Other model inputs are summarised in Table 2. Persistence on mirabegron was extrapolated from the study of Wagg et al. [21], in which data were extracted via medical practice software and anonymised from the records of $>1,200,000$ registered patients, of whom 4,833 had documented OAB. An additional 12-week observational study of OAB patients in Spain showed that $24 \%$ of patients who changed treatment did so because of adverse events [22]; these results were consistent with those of a large US survey of patients with OAB [13]. As no real-life data are available for persistence with mirabegron, the model assumed that discontinuation rates for patients without adverse events were similar for mirabegron and its comparator. The probability of switching to next-line therapy was obtained from an analysis based on the UK general practice research database [23]. The base-case frequency (Table 2) was derived from 5,424 patients who received first-line tolterodine, of whom $68.92 \%$ discontinued and $26.06 \%$ switched to another medication (most frequently oxybutynin).

No data are available in the literature regarding the probability of restarting treatment after a period of no treatment. We assumed an annual probability of $50 \%$ (monthly probability of $5.6 \%$ ). The $79 \%$ probability of improvement of symptoms after BTX injection was based on a published cost-effectiveness analysis comparing BTX to antimuscarinic therapy [24].

\subsubsection{Adverse Events}

Monthly probabilities of adverse events were derived from SCORPIO [15]. Patients were assumed to experience dry mouth or constipation (Table 2). Other adverse events were excluded based on the results of a European cross-sectional survey that showed that these two events are the main drivers of adverse event-related treatment discontinuation with antimuscarinic therapy [25] and the finding that the events reported most frequently with mirabegron occur at a similar incidence with placebo [15].

\subsubsection{Utilities}

Utility values according to symptom severity and adverse events were derived from EuroQol 5-Dimension (EQ-5D) index scores, based on the UK time trade-off tariff [26], 
Table 2 Model inputs for the base-case scenario. Also shown are ranges used for the probabilistic sensitivity analysis

\begin{tabular}{|c|c|c|c|}
\hline Parameter & Base case value & Sensitivity analysis range & References \\
\hline \multicolumn{4}{|l|}{ Discontinuation and switch } \\
\hline \multicolumn{4}{|l|}{ Treatment discontinuation } \\
\hline Without AEs & $6.4 \%$ per month & $3.0-14.5 \%$ & $\begin{array}{l}\text { Base case and upper limit: Wagg et al. [21]; } \\
\text { Sánchez-Ballester et al. [22]; lower limit: assumption }\end{array}$ \\
\hline With AEs & $90 \%$ per month & $50-100 \%$ & Expert opinion \\
\hline Treatment switch $^{\mathrm{a}}$ & $26.1 \%$ & $15.3-50.0 \%$ & $\begin{array}{l}\text { Base case: Odeyemi et al. [23]; sensitivity analysis: } \\
\text { D'Souza et al. [38]/assumption }\end{array}$ \\
\hline Treatment restart $^{\mathrm{b}}$ & $5.6 \%$ per month & $0-20.0 \%$ & Expert opinion \\
\hline BTX injection & $0.01 \%$ per month & $0-0.05 \%$ & Expert opinion \\
\hline Success with BTX & $79 \%$ & $50-100 \%$ & Wu et al. [24] \\
\hline \multicolumn{4}{|l|}{ Adverse events } \\
\hline \multicolumn{4}{|l|}{ Dry mouth } \\
\hline Mirabegron $50 \mathrm{mg}$ & $2.8 \%$ & $2.1-3.5 \%$ & SCORPIO [15] \\
\hline Tolterodine ER $4 \mathrm{mg}$ & $10.1 \%$ & $8.7-11.5 \%$ & SCORPIO [15] \\
\hline \multicolumn{4}{|l|}{ Constipation } \\
\hline Mirabegron $50 \mathrm{mg}$ & $1.6 \%$ & & SCORPIO [15] \\
\hline Tolterodine ER $4 \mathrm{mg}$ & $2.0 \%$ & & SCORPIO [15] \\
\hline
\end{tabular}

collected in SCORPIO [15]. A linear regression model of EQ-5D utility as a function of symptom severity was developed as described in detail in the Electronic Supplementary Material and Supplementary Table 4. The utility decrement for adverse events was an average, weighted according to the treatment-specific probabilities for the different adverse events. Utilities derived from the overactive bladder questionnaire (OAB-q), using the algorithm developed by Yang et al. [27], were also used.

\subsubsection{Resource Utilisation and Costs}

Resources and associated costs included in the model are from a UK NHS payer perspective (Table 3). Drug therapy, primary care visits, specialist (urologist) visits, BTX injections and incontinence pads were accounted for. Patients were assumed to use one tablet of mirabegron per day; wastage or partial compliance was not accounted for. Pad utilisation was tiered according to incontinence severity.

Costs are presented in 2012 British pounds ( $\mathfrak{E}$ ) and are summarised together with sources in Table 3. An annual discount rate of $3.5 \%$ was applied to costs and health benefits.

\subsection{Model Outputs}

The model was designed to output (i) average annual cumulative costs by treatment strategy; (ii) quality-adjusted life-years (QALYs) gained by using a particular treatment strategy; (iii) and incremental cost-effective ratios (ICERs) expressed as incremental cost per QALY gained.

\subsection{Sensitivity and Subgroup Analyses}

Sensitivity analyses evaluated the impact of assumptions used in the model and variability surrounding model inputs. For deterministic sensitivity analyses, one variable or assumption was changed at a time. One-way sensitivity analyses were conducted on all model parameters associated with uncertainty: proportions of patients by severity level at baseline; transition probabilities between symptom levels; utilities by symptom level; probabilities of treatment-related events; probabilities related to BTX injections; and probabilities associated with adverse events and resource use. Outcomes were computed using confidence limits around each parameter or other fixed values.

A probabilistic sensitivity analysis was also performed. Appropriate statistical distributions were assigned to input parameters (Table 2). Values were drawn at random from statistical distributions for these variables and the process was iterated 5,000 times to provide distributions for ICERs. Cost-effectiveness acceptability curves (CEACs) were generated at various willingness-to-pay (WTP) thresholds. The probabilistic analysis was programmed in visual basic applications for Excel.

Finally, because indirect costs were not included in the model, a sensitivity analysis including indirect costs valued 
Table 3 Modelled resource use and costs for the base-case scenario. Also shown are ranges used for the probabilistic sensitivity analysis

\begin{tabular}{llll}
\hline Parameter & Base case value & Sensitivity analysis range & References \\
\hline Resource use & & & \\
Pad utilisation & & & \\
$\quad$ Incontinence level 1 & 0.17 & $0.150-0.198$ & SCORPIO [15] \\
Incontinence level 2 & 0.75 & $0.687-0.817$ & $1.282-1.486$ \\
Incontinence level 3 & 1.38 & $1.745-2.039$ & Expert opinion \\
Incontinence level 4 & 1.89 & $3.167-3.511$ & Cardozo et al. [31]/assumption \\
Incontinence level 5 & 3.34 & $0-2$ & Expert opinion \\
GP consultations & 1 visit at start and at every switch & $1-3$ & BNF 2011/12 [39] \\
Specialist consultations & 1.5 visits at start and at every switch & $0-0.34$ & BNF 2011/12 [39] \\
BTX injections & & & \\
Costs & 0.17 per month & & BNF 2011/12 [39] \\
Monthly acquisition cost & & & PSSRU 2010 [40] \\
Mirabegron 50 mg & $£ 29.40$ & & NHS payment 2010-2011 \\
Tolterodine ER 4 mg & $£ 28.01$ & & Nottingham Urology Group [41] \\
Solifenacin 5 mg & $£ 28.00$ & & AgeUK [42] \\
GP consultation & $£ 36.00$ & & \\
Specialist visit & $£ 96.00$ & $£ 1,158 / £ 964$ & \\
BTX injection/reinjection & $£ 0.16$ & & \\
Incontinence pad & & & \\
\hline
\end{tabular}

BNF British National Formulary, BTX botulinum toxin, GP general practitioner, PSSRU Personal Social Services Research Unit

${ }^{\text {a }}$ Following successful first injection

Table 4 Predicted costs (2012) and cost-effectiveness outcomes for the base-case analysis (general OAB population)

\begin{tabular}{lccc}
\hline Parameter & Mirabegron strategy & Tolterodine strategy & Cost difference/incremental change \\
\hline Predicted costs (£) & & & 107.72 \\
Drug acquisition & 451.43 & 343.70 & -28.50 \\
Other OAB treatment & 364.92 & 393.42 & -4.45 \\
GP visit & 101.38 & 105.83 & -17.78 \\
Specialist visit (initial + follow-up) & 405.83 & 423.31 & -9.11 \\
BTX (initial + repeat injections) & 93.66 & 102.78 & -10.00 \\
Incontinence pads & 228.70 & 238.71 & 37.88 \\
Total & $1,645.62$ & $1,607.75$ & 37.88 \\
Cost effectiveness & & & 0.009 \\
Total costs (£) & $1,645.62$ & $1,607.75$ & 4,386 \\
QALYs & 3.764 & 3.755 & \\
ICER (£/QALY gained per patient) & & & \\
\hline
\end{tabular}

$B T X$ botulinum toxin, $G P$ general practitioner, $I C E R$ incremental cost-effectiveness ratio, $O A B$ overactive bladder syndrome, $Q A L Y$ qualityadjusted life-year

using the human capital approach to determine the effect on the ICER estimate was also performed. Absenteeism was derived from the percentage work time missed, assessed for each patient in the SCORPIO trial using the work productivity and activity impairment (WPAI) questionnaire [28].

Subgroup analyses were also performed.

\section{Results}

\subsection{Base-Case Scenario}

On average, patients treated with tolterodine discontinued treatment earlier than those treated with mirabegron (329.79 vs. 391.79 days, respectively). Total costs per 
patient over 5 years were $£ 1,645.62$ for the mirabegron strategy and $£ 1,607.75$ for tolterodine from the UK NHS perspective. Medication costs were higher with mirabegron than with tolterodine ( $£ 451.43$ vs. $£ 343.70$ ), mainly due to the differences in time to discontinuation (Table 4). This was partly offset by the reduced costs of specialist visits and incontinence pad utilisation under the mirabegron strategy.

Based on EQ-5D utilities, the mirabegron strategy was associated with a gain of 0.009 QALYs, and an additional cost of $£ 37.88$ over the modelled 5-year period. The resulting ICER was below the WTP threshold of $£ 20,000 /$ QALY gained, at $£ 4,386 /$ QALY gained (Table 4). Based on OAB-q utilities, the number of QALYs gained was 0.01259 , leading to an ICER of $£ 3,008 /$ QALY gained.

\subsection{Subgroup Analyses}

Results of cost-effectiveness analyses for different subgroups are summarised in Table 5. Mirabegron was found to be cost effective compared to tolterodine ER $4 \mathrm{mg}$ in all subgroups except the subgroup comprising men (ICER $£ 38,708$ ). The benefit of mirabegron $50 \mathrm{mg}$ was greatest for patients dissatisfied because of adverse events, with an estimated gain of 0.0186 QALYs (EQ-5D) at a cost of $£ 28.37$ over 5 years, yielding an ICER of $£ 1,528 /$ QALY gained. ICERs across the other subgroups ranged from $£ 3,091 /$ QALY gained (women only) to $£ 5,736 /$ QALY gained (elderly).

\subsection{Deterministic Sensitivity Analysis}

For the sensitivity analyses, health state utilities based on EQ-5D were used. Detailed results are shown in the tornado chart in Fig. 2. The model was most sensitive to the transition probabilities between symptom levels of incontinence and micturition for mirabegron and tolterodine, the distribution of patients by micturition and incontinence severity level at baseline, and the monthly probability of restarting treatment. However, mirabegron was cost effective or dominant compared with tolterodine in all scenarios. The ICER was also found to vary little (from $£ 4,092$ to 4,698/QALY gained) when the discount rate was varied from 0 to $6.0 \%$ for costs and outcomes.

\subsection{Probabilistic Sensitivity Analysis}

The probabilistic sensitivity analysis results are represented in the CEAC shown in Fig. 3. At the WTP threshold of $£ 20,000$ /QALY gained, the probability of mirabegron $50 \mathrm{mg}$ being cost effective relative to tolterodine ER $4 \mathrm{mg}$ was $89.4 \%$.

\subsection{Sensitivity Analysis for Indirect Costs}

The inclusion of indirect costs resulted in lower ICERs in all comparisons, with mirabegron being dominant in all populations except the previously treated and men subgroups, in which the ICERS were below the WTP threshold of $£ 20,000 / Q A L Y$ gained (data not shown).

\section{Discussion}

The base-case analysis in the present model showed that mirabegron $50 \mathrm{mg} /$ day is cost effective at the WTP thresholds of $£ 20,000 / \mathrm{QALY}$ and $£ 30,000 / \mathrm{QALY}$ generally applied by the UK National Institute for Health and Clinical Excellence [29]. The one-way deterministic sensitivity analysis demonstrated that the ICER remained below the WTP threshold of $£ 20,000$ whenever a parameter was modified. The probabilistic sensitivity analysis, which tested uncertainty around the model parameters through Monte Carlo simulations using appropriate distributions, demonstrated a high probability $(89.4 \%)$ that mirabegron $50 \mathrm{mg} /$ day would be cost effective compared with

Table 5 Cost-effectiveness results by subgroup (UK NHS perspective)

\begin{tabular}{|c|c|c|c|}
\hline Subgroup & Incremental costs $(£)$ & Incremental QALYs & ICER (£/QALY gained) \\
\hline General population & 37.88 & 0.0086 & 4,386 \\
\hline Previously treated & 38.07 & 0.0099 & 3,836 \\
\hline Dissatisfied because of lack of efficacy & 40.27 & 0.0091 & 4,446 \\
\hline Dissatisfied because of adverse events & 28.37 & 0.0186 & 1,528 \\
\hline Incontinent & 32.36 & 0.0124 & 2,620 \\
\hline Elderly & 35.19 & 0.0061 & 5,736 \\
\hline Treatment naïve & 40.27 & 0.0076 & 5,315 \\
\hline Women & 37.73 & 0.0122 & 3,091 \\
\hline Men & 43.96 & 0.0011 & 38,708 \\
\hline
\end{tabular}

ICER incremental cost-effectiveness ratio, $Q A L Y$ quality-adjusted life-year 


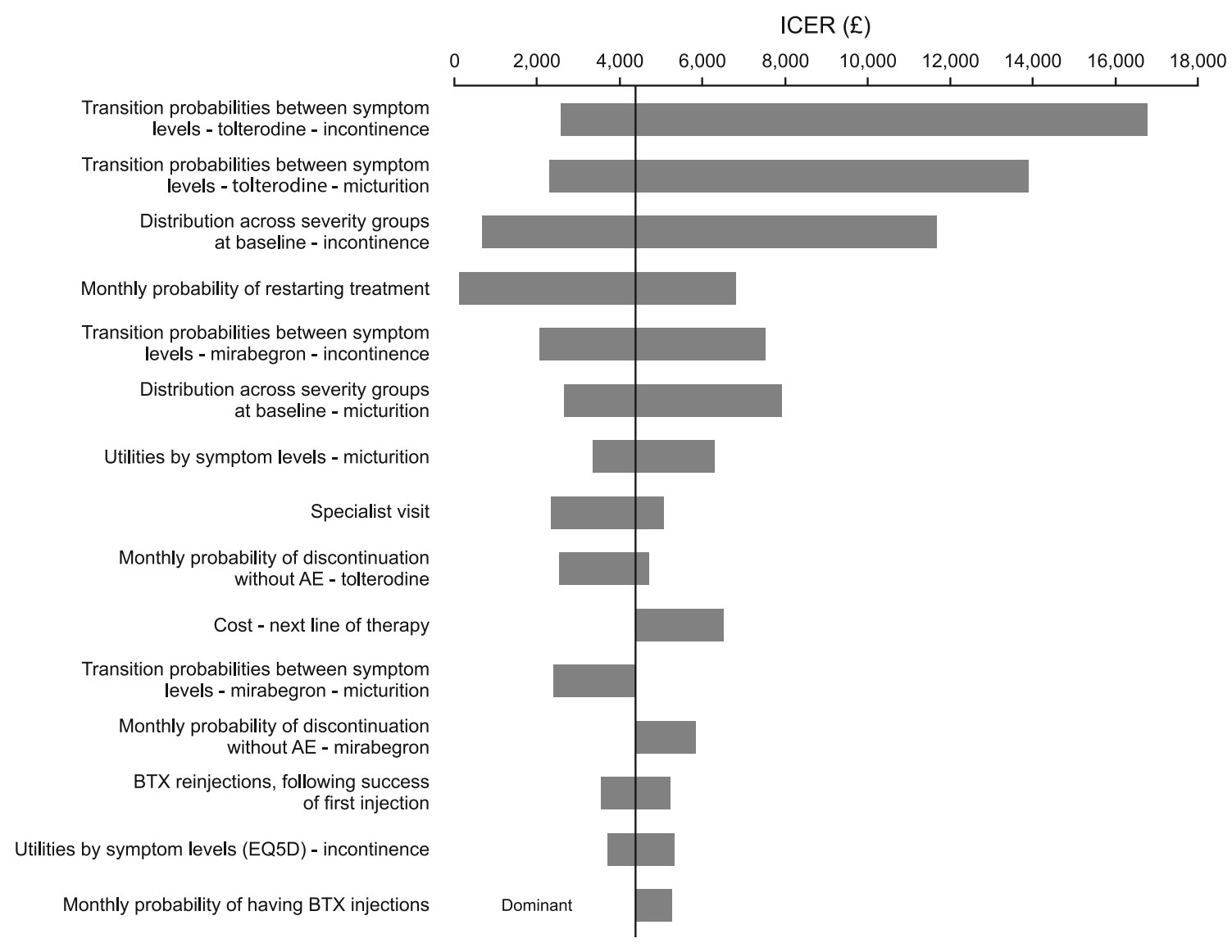

Fig. 2 Deterministic sensitivity analysis. $A E$ adverse event, $B T X$ botulinum toxin, EQ5D European Quality of Life questionnaire in five dimensions, ICER incremental cost-effectiveness ratio

Fig. 3 Cost-effectiveness acceptability curve for mirabegron $50 \mathrm{mg}$ vs tolterodine extended release $4 \mathrm{mg}$; general $\mathrm{OAB}$ population. $O A B$ overactive bladder syndrome, $Q A L Y$ qualityadjusted life year

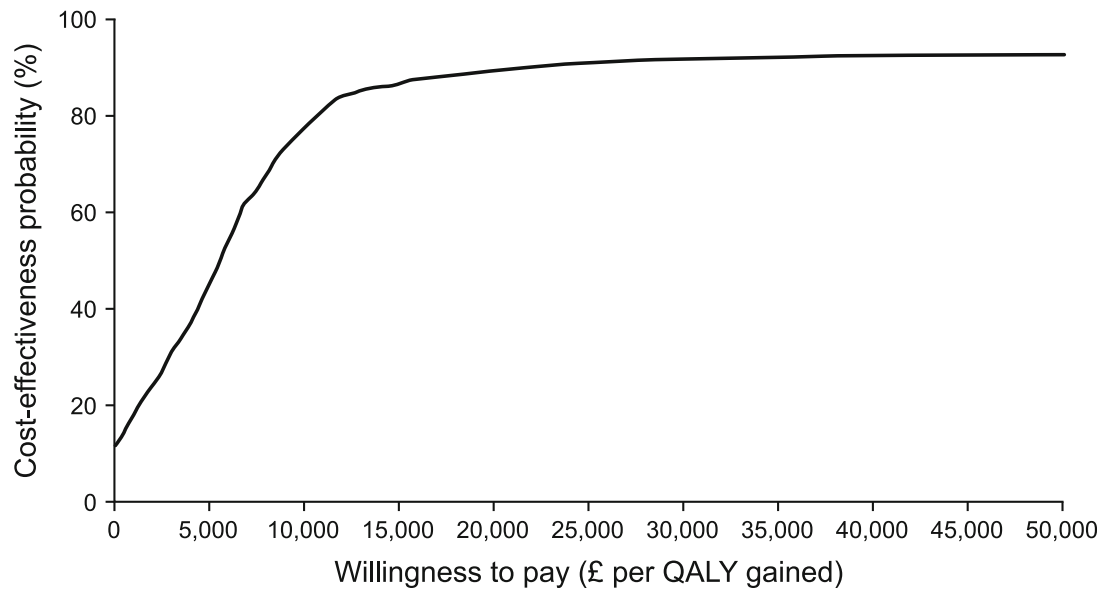

tolterodine ER $4 \mathrm{mg} /$ day at the generally accepted costeffectiveness threshold of $£ 20,000 /$ QALY gained. Overall, the subgroup analyses also supported the primary result.

To the best of our knowledge, no other economic analyses of mirabegron in the treatment of OAB with which to compare our findings are available in the literature. However, previously published cost-effectiveness models comparing tolterodine ER $4 \mathrm{mg}$ with other antimuscarinic agents suggest that our results are plausible. Speakman et al. [30] developed a 1-year Markov model to evaluate the cost effectiveness of solifenacin $5 \mathrm{mg}$ and $10 \mathrm{mg}$ compared with tolterodine (immediate release $2 \mathrm{mg}$ twice daily or ER $4 \mathrm{mg}$ daily) in OAB from the UK NHS perspective, while a 1-year model developed by Cardozo et al. [31] assessed the cost effectiveness of solifenacin against other antimuscarinic agents commonly used in UK 
clinical practice, including tolterodine. The predicted total annual costs per patient for tolterodine were $£ 526$ and $£ 480$, in the Speakman and Cardoza studies respectively $[30,31]$, compared with an annual cost of $£ 620$ in our model when run over a 1-year time horizon. The difference in costs was mainly due to our assumption that all patients initiating a new treatment would consult a specialist. The respective numbers of QALYs for 1 year with tolterodine were 0.705 and $0.710[30,31]$, compared with 0.814 in our model, with the difference being due to our use of a new set of utilities based on EQ-5D data collected in clinical trials of mirabegron. However, the difference between the maximum and minimum utilities in this new model is similar to the range in the earlier model of Speakman et al. [30] (0.145 vs. 0.144). Furthermore, the QALY gain based on our model (0.009) is consistent with these and other previous studies that used EQ-5D (0.004 [30], 0.014 [32] and 0.004 [33]). This suggests that the magnitude of the QALY gain is meaningful in OAB, although it should be noted that as a generic tool EQ-5D is relatively insensitive to changes in $\mathrm{OAB}$ symptoms. An analysis mapping EQ$5 \mathrm{D}$ scores to those obtained with the OAB-specific OAB$5 \mathrm{D}$ instrument has shown that scores are higher with $\mathrm{OAB}-$ $5 \mathrm{D}$, suggesting that the magnitude of any differences would also be higher [34].

In other analyses carried out from a UK health system perspective, Hakkaart et al. [32] found incremental costs per QALY gained over placebo to be $£ 17,602$ and $£ 24,464$ with solifenacin $5 \mathrm{mg}$ and $10 \mathrm{mg}$ daily, respectively, in a Markov model run over a 12-month time horizon in patients with $\mathrm{OAB}$, and Getsios et al. [33] showed that a sustained-release formulation of oxybutynin $10 \mathrm{mg}$ dominated immediate-release tolterodine $4 \mathrm{mg}$. Another analysis has suggested that immediate- and sustained-release oxybutynin and tolterodine ER are all cost-effective options for managing urge incontinence from a UK NHS perspective [35]. These findings suggest strongly that economic comparisons of mirabegron with these and other antimuscarinic agents will be of considerable interest to clinicians and healthcare policy makers. In addition to the analysis reported here, a model based on a mixed treatment comparison (MTC) of mirabegron and antimuscarinic therapy for $\mathrm{OAB}$ has also been reported [36, 37]. This demonstrated that the efficacy of mirabegron $50 \mathrm{mg}$ in $\mathrm{OAB}$ patients is similar to that of most approved antimuscarinic drugs in the general $\mathrm{OAB}$ population and that it has the most favourable tolerability profile, with a significantly lower incidence of dry mouth than any antimuscarinic agent and the same incidence of constipation as placebo [36].

A key strength of our model is that it was designed to capture the effects on HRQoL of variations in symptom severity over time, as well as the impact of treatment discontinuation and switching on costs and health outcomes. In contrast, previous Markov models for this type of analysis have been based on the extensively applied model developed by Kobelt et al. [19], which consists of five health states representing different levels of disease severity with a single absorbing state for drop-outs, who were considered to remain off treatment. We found that the main symptoms of $\mathrm{OAB}$ (micturitions and incontinence) had a significant influence on utility independently of each other, with moderate correlations between changes in these symptoms. The progression of these symptoms over time was therefore modelled separately. In addition, we attached increased importance to the modelling of patient pathways after treatment discontinuation, because of the high rates of discontinuation and treatment switching observed in patients with OAB. Finally, the use of a 5-year time horizon, at which point $<5 \%$ of patients remained on treatment in the model, and performing sensitivity analyses based on other time-points, at which the conclusions regarding the cost-effectiveness of mirabegron held, ensured that the model reflected the costs and outcomes of managing a chronic condition. Therefore, we believe that our model more accurately represents the clinical management of $\mathrm{OAB}$.

Another strength is that we have analysed the cost effectiveness of therapy in various relevant patient subgroups. These analyses showed that mirabegron was consistently cost effective in most of these subgroups.

In contrast, possible limitations include the assumption that discontinuation rates due to reasons other than adverse events were similar for mirabegron and tolterodine, because no real-life data on persistence with mirabegron are available. We believe that this is a conservative assumption because the MTC demonstrated that the probability of mirabegron being more effective than tolterodine in terms of micturition and incontinence is 87.4 and $88.3 \%$, respectively [36]. Moreover, no data on the probability of BTX being used to treat OAB following drug therapy and no data on the numbers of visits to specialists were available. Again, we took a conservative approach and assumed that the proportions of patients receiving BTX were small; sensitivity analysis showed that the ICER would increase modestly if no patients received BTX and that mirabegron remained cost effective. The impact of varying the numbers of visits to specialists was also assessed in a sensitivity analysis, which showed that this affected the absolute results, but not sufficiently to change the conclusion that mirabegron is cost effective. Furthermore, number of specialist visits was not one of the main parameters to which the model was sensitive.

The model used in our analysis included direct healthcare costs only, in line with the requirements of UK guidelines for pharmacoeconomic assessments. The failure 
to include indirect costs in the model represents another potential limitation, but a sensitivity analysis including indirect costs showed that ICERs were lower in all comparisons, with mirabegron being dominant in all populations except the previously treated and men subgroups.

\section{Conclusion}

In conclusion, from a UK NHS perspective, mirabegron $50 \mathrm{mg} /$ day appears to be a cost-effective treatment strategy compared with tolterodine ER $4 \mathrm{mg} /$ day for the general population of adults with $\mathrm{OAB}$ and for subgroups including those previously treated and those who are treatment naive, patients dissatisfied due to lack of efficacy or adverse events, patients who are incontinent, the elderly, and women.

Acknowledgments This study was sponsored by Astellas Pharma Global Development. Medical writing was provided by Andy Noble of Bioscript Medical, and was funded by Astellas Pharma Global Development. S. Aballéa, K. Desroziers and M. Toumi are employees of Creativ-Ceutical SARL, which was contracted by Astellas Pharma to perform this research. K. Maman, J. Nazir, I. A. O. Odeyemi, A. Garnham and Z. Hakimi are employees of Astellas Pharma.

Open Access This article is distributed under the terms of the Creative Commons Attribution Noncommercial License which permits any noncommercial use, distribution, and reproduction in any medium, provided the original author(s) and the source are credited.

\section{References}

1. Abrams P, Artibani W, Cardozo L, Dmochowski R, van Kerrebroeck P, Sand P, et al. Reviewing the ICS 2002 terminology report: the ongoing debate. Neurourol Urodyn. 2009;28:287.

2. Coyne KS, Payne C, Bhattacharyya SK, Revicki DA, Thompson C, Corey R, et al. The impact of urinary urgency and frequency on health-related quality of life in overactive bladder: results from a national community survey. Value Health. 2004;7:455-63.

3. Abrams P, Cardozo L, Fall M, Griffiths D, Rosier P, Ulmsten U, et al. The standardisation of terminology of lower urinary tract function: report from the Standardisation Sub-committee of the International Continence Society. Neurourol Urodyn. 2002;21: $167-78$.

4. Irwin DE, Kopp ZS, Agatep B, Milsom I, Abrams P. Worldwide prevalence estimates of lower urinary tract symptoms, overactive bladder, urinary incontinence and bladder outlet obstruction. BJU Int. 2011;108:1132-8.

5. Milsom I, Abrams P, Cardozo L, Roberts RG, Thuroff J, Wein AJ. How widespread are the symptoms of an overactive bladder and how are they managed? A population-based prevalence study. BJU Int. 2001;87:760-6.

6. Coyne KS, Sexton CC, Irwin DE, Kopp ZS, Kelleher CJ, Milsom I. The impact of overactive bladder, incontinence and other lower urinary tract symptoms on quality of life, work productivity, sexuality and emotional well-being in men and women: results from the EPIC study. BJU Int. 2008;101:1388-95.
7. Coyne KS, Sexton CC, Kopp ZS, Ebel-Bitoun C, Milsom I, Chapple C. The impact of overactive bladder on mental health, work productivity and health-related quality of life in the UK and Sweden: results from EpiLUTS. BJU Int. 2011;108:1459-71.

8. Nicolson P, Kopp Z, Chapple CR, Kelleher C. It's just the worry about not being able to control it! A qualitative study of living with overactive bladder. Br J Health Psychol. 2008;13:343-59.

9. Gormley EA, Lightner DJ, Burgio KL, Chai TC, Clemens JQ, Culkin DJ, et al. Diagnosis and treatment of overactive bladder (non-neurogenic) in adults: AUA/SUFU guideline. J Urol. 2012;188(6 Suppl):2455-63.

10. National Institute for Health and Care Excellence. Lower urinary tract symptoms. The management of lower urinary tract symptoms in men. London: National Institute for Health and Care Excellence; 2010.

11. National Institute for Health and Care Excellence. Urinary incontinence. The management of urinary incontinence in women. London: National Institute for Health and Care Excellence; 2013.

12. Madhuvrata P, Cody JD, Ellis G, Herbison GP, Hay-Smith EJ. Which anticholinergic drug for overactive bladder symptoms in adults. Cochrane Database Syst Rev. 2012;1:CD005429.

13. Benner JS, Nichol MB, Rovner ES, Jumadilova Z, Alvir J, Hussein M, et al. Patient-reported reasons for discontinuing overactive bladder medication. BJU Int. 2010;105:1276-82.

14. Kumar V, Templeman L, Chapple CR, Chess-Williams R. Recent developments in the management of detrusor overactivity. Current Opin Urol. 2003;13:285-91.

15. Khullar V, Amarenco G, Angulo JC, Cambronero J, Høye K, Milsom I, et al. Efficacy and tolerability of mirabegron, a $\beta(3)$ adrenoceptor agonist, in patients with overactive bladder: results from a randomised European-Australian phase 3 trial. Eur Urol. 2013;63:283-95.

16. Herschorn S, Barkin J, Castro-Diaz D, Frankel JM, Espuna-Pons $\mathrm{M}$, Gousse AE, et al. A phase III, randomized, double-blind, parallel-group, placebo-controlled, multicentre study to assess the efficacy and safety of the $\beta_{3}$ adrenoceptor agonist, mirabegron, in patients with symptoms of overactive bladder. Urology. 2013;82:313-20.

17. Nitti VW, Auerbach S, Martin N, Calhoun A, Lee M, Herschorn S. Results of a randomized phase III trial of mirabegron in patients with overactive bladder. J Urol. 2013;189:1388-95.

18. Chapple CR, Kaplan SA, Mitcheson D, Klecka J, Cummings J, Drogendijk T, et al. Randomized double-blind, active-controlled phase 3 study to assess 12-month safety and efficacy of mirabegron, a $\beta(3)$-adrenoceptor agonist, in overactive bladder. Eur Urol. 2013;63:296-305.

19. Kobelt G, Jönsson L, Mattiasson A. Cost-effectiveness of new treatments for overactive bladder: the example of tolterodine, a new muscarinic agent: a Markov model. Neurourol Urodyn. 1998;17:599-611.

20. Balkrishnan R, Bhosle MJ, Camacho FT, Anderson RT. Predictors of medication adherence and associated health care costs in an older population with overactive bladder syndrome: a longitudinal cohort study. J Urology. 2006;175:1067-71 (discussion 71-2).

21. Wagg A, Compion G, Fahey A, Siddiqui E. Persistence with prescribed antimuscarinic therapy for overactive bladder: a UK experience. BJU Int. 2012;110:1767-74.

22. Sánchez-Ballester F, Miranda P, Lizarraga I, Rejas J, Arumi D. Therapeutic benefit in patients switching tolterodine to other novel antimuscarinic agents. Actas Urol Esp. 2014;38:156-63.

23. Odeyemi IA, Dakin HA, O'Donnell RA, Warner J, Jacobs A, Dasgupta P. Epidemiology, prescribing patterns and resource use associated with overactive bladder in UK primary care. Int J Clin Pract. 2006;60:949-58. 
24. Wu JM, Siddiqui NY, Amundsen CL, Myers ER, Havrilesky LJ, Visco AG. Cost-effectiveness of botulinum toxin a versus anticholinergic medications for idiopathic urge incontinence. J Urol. 2009;181:2181-6.

25. Compion G, Jackson J, Janes J. Reasons for switching antimuscarinic therapy: results from a European cross-sectional survey of physicians, and patients with OAB. In: 27th Annual Congress of the European Association of Urology: Paris; 2012.

26. Dolan P. Modeling valuations for EuroQol health states. Med Care. 1997;35:1095-108.

27. Yang Y, Brazier J, Tsuchiya A, Coyne K. Estimating a preference-based single index from the Overactive Bladder Questionnaire. Value Health. 2009;12:159-66.

28. Reilly MC, Zbrozek AS, Dukes EM. The validity and reproducibility of a work productivity and activity impairment instrument. Pharmacoeconomics. 1993;4:353-65.

29. Devlin N, Parkin D. Does NICE have a cost-effectiveness threshold and what other factors influence its decisions? A binary choice analysis. Health Econ. 2004;13:437-52.

30. Speakman M, Khullar V, Mundy A, Odeyemi I, Bolodeoku J. A cost-utility analysis of once daily solifenacin compared to tolterodine in the treatment of overactive bladder syndrome. Curr Med Res Opin. 2008;24:2173-9.

31. Cardozo L, Thorpe A, Warner J, Sidhu M. The cost-effectiveness of solifenacin vs fesoterodine, oxybutynin immediate-release, propiverine, tolterodine extended-release and tolterodine immediate-release in the treatment of patients with overactive bladder in the UK National Health Service. BJU Int. 2010;106:506-14.

32. Hakkaart L, Verboom P, Phillips R, Al MJ. The cost utility of solifenacin in the treatment of overactive bladder. Int Urol Nephrol. 2009;41:293-8.

33. Getsios D, Caro JJ, Ishak KJ, El-Hadi W, Payne K, O'connel M, et al. Oxybutynin extended release and tolterodine immediate release : a health economic comparison. Clin Drug Investig. 2004;24:81-8.

34. Desroziers K, Aballea S, Maman K, Nazir J, Odeyemi I, Hakimi Z. Estimating EQ-5D and OAB-5D health state utilities for patients with overactive bladder. Health Qual Life Outcomes. 2013;11:200.

35. Hughes DA, Dubois D. Cost-effectiveness analysis of extendedrelease formulations of oxybutynin and tolterodine for the management of urge incontinence. Pharmacoeconomics. 2004;22: 1047-59.

36. Maman K, Aballea S, Nazir J, Desroziers K, Neine ME, Siddiqui E, et al. Comparative efficacy and safety of medical treatments for the management of overactive bladder: a systematic literature review and mixed treatment comparison. Eur Urol. 2013;65:755-65.

37. Maman K, Neine M, Briquet B, Nazir J, Odeyemi IAO, Hakimi Z, et al. Cost-effectiveness of mirabegron compared with antimuscarinics for the treatment of patients with overactive bladder in the UK. In: ISPOR 16th Annual European Congress. Dublin; 2013: PUK22.

38. D’Souza AO, Smith MJ, Miller LA, Doyle J, Ariely R. Persistence, adherence, and switch rates among extended-release and immediate-release overactive bladder medications in a regional managed care plan. J Manag Care Pharm. 2008;14:291-301.

39. BNF.org. British National Formulary. http://www.bnf.org/bnf/ index.htm. Accessed 17 Dec 2013.

40. Personal Social Services Research Unit. Unit Costs of Health and Social Care 2010. http://www.pssru.ac.uk/pdf/uc/uc2010/ uc2010_s10.pdf. Accessed 27 June 2014.

41. Nottingham Urology Group. Bladder BOTOX Injections. http:// www.nottinghamurologygroup.co.uk/treatments/bladder-botoxinjections. Accessed 17 Dec 2013.

42. Age UK. The latest incontinence products $\&$ incontinence advice. http://www.ageukincontinence.co.uk/. Accessed 17 Dec 2013. 